\title{
Predation and Mergers: Is Merger Law Counterproductive?
}

\author{
Lars Persson* \\ The Research Institute of Industrial Economics
}

August 2, 1999

\begin{abstract}
This paper studies the interaction between the incentives for predation and mergers. I show that the incentive for predation in an oligopoly is limited by the subsequent competition for the prey. This bidding competition is especially fierce when the prey's assets exert strong negative externalities on rivals. Firms may therefore prefer to predate to destroy the prey's assets, rather than just its financial viability. The paper also demonstrates that predation may be preferred to an immediate merger for two reasons. First, by predating, firms may share the costs of eliminating a rival and circumvent the free-riding problem associated with mergers, and second destructive predation helps firms avoid the bidding competition. It is also shown that a restrictive merger policy may be counterproductive, since it may increase the incentives for predation by helping predators avoid the bidding competition. Moreover, the incentive for predation under the US failing firm defense might be even stronger, since it allows mergers but limits the bidding competition.
\end{abstract}

JEL CLASSIFICATION NO: K21, L12, L41

Keywords: Mergers; Predation; Merger Law; Failing Firm Defense.

*I am grateful for helpful discussions with David Domeij, Sven-Olof Fridolfsson, Henrik Horn, Dan Kovenock, Massimo Motta and Johan Stennek, and by participants in seminars at the Institute for International Economic Studies, the Universitat Pompeu Fabra, Purdue University, IRIS and the University of Maryland, ECARE at Universite Libre de Bruxelles, and Instituto de Analisis Economico (CSIC). Financial support by the Bank of Sweden Tercentenary Foundation, and Tom Hedelius' and Jan Wallander's Research Foundations, is gratefully acknowledged. Address: The Research Institute of Industrial Economics, Box 5501, SE-114 85 Stockholm, Sweden. Email: larsp@iui.se. (pme-120.tex) 


\section{Introduction}

Firms can basically use two types of business strategies to eliminate rivals; they can either merge with them, or predate in order to induce exit. The literature on mergers emphasizes that firms in an oligopoly have limited possibilities of eliminating rivals by mergers, since the costs of such concentration are mainly carried by the acquiring firm, while the gains are spread to all firms in the industry. This was first pointed out by Stigler (1950) who wrote that "...the major difficulty in forming a merger is that it is more profitable to be outside a merger than to be a participant." This idea was later formalized by Kamien and Zang (1990) who showed that there are limited possibilities for concentration by mergers when these take place through an auction. ${ }^{1}$ Accordingly, the need for merger control should be very limited. But the merger literature neglects the possibility that predation may interact with merger incentives.

The predation literature has studied the effectiveness of predation in situations where merger is an alternative. McGee (1958) claimed that it cannot then be rational to engage in predatory behavior, since the predator and the prey can avoid the costs of predation and share the surplus in an immediate merger. Thus, predation should be of no concern for competition policy, when mergers are allowed. The above argument was criticized by Yamey (1972), on the ground that the buyout price might be lower if a potential buyer can predate a "weaker" rival. ${ }^{2}$ According to this reasoning, the incentive for merger increases if predation is an option. This idea was formalized by Saloner (1987), who showed that predation may make the target lower its beliefs about its future profit, which will weaken its bargaining position in the merger negotiation taking place after predation, and thus increases the incentives for mergers. One weakness in the predation literature that studies the incentives for predation for mergers is that it is solely concerned with duopoly situations and thus with the incentives for complete monopolization. As showed by the merger literature, the incentives for mergers are radically influenced by the existence of a larger number of firms. One may therefore also assume that the incentives for predation for mergers depend on the number of

\footnotetext{
${ }^{1}$ The traditional analysis of incentives for mergers, originated by Salant et al (1983), and developed by e.g. Deneckere and Davidson (1985), Perry and Porter (1985), and McAfee and Williams (1992), considers a merger between an arbitrary number of firms in the context of some particular oligopoly model. The merger pattern is thus not endogenously determined. The general emerging picture from these studies is that the concentration induced by mergers might not be a sufficient incentive for mergers, since concentration may actually reduce joint profits of the merging firms relative to the initial equilibrium.

${ }^{2}$ Yamey criticized McGee on two grounds. His second argument was that it might be advantageous for the predator to signal aggressive behavior in order to improve future interaction. This argument has later been formalized in two types of asymmetric information models: Signaling models and reputation models.
} 
firms in the industry.

The purpose of the present paper is to study the interaction between incentives for predation and incentives for merger in a multi-firm setting. In order to derive some conclusions about the appropriate design of merger law, I will also show how the incentives for predation and mergers may depend on the property of the merger law. To this end, I combine two models of endogenous merger formation, created by Kamien and Zang (1990) and Jehiel and Moldovanu (1996) respectively, with an oligopoly model including the possibility for predation. The merger formation is depicted as an auction, where the owners simultaneously post bids for other firms and state an asking price for their own firm. This model is described in section 2 .

In section 3.1, I show that there are two fundamental differences between predation for merger for monopoly and predation for merger giving rise to an oligopoly. First, predation in a multi-firm setting helps the firms avoid the freeriding problem associated with elimination by merger. This tends to increase the incentives for mergers (Proposition 1). Thus, the paper demonstrates that the incentives for mergers increase if predation is an option. ${ }^{3}$

Second, predation in a multi-firm setting is followed by a fierce bidding competition for the prey's assets. Consequently, the price of the prey in an oligopoly might be so high that the incentive for predation for merger vanishes. The bidding competition is most harmful to predators when the use of the prey's assets exerts strong negative externalities on rivals, since the potential buyers are then willing to pay a high price for the prey in order to prevent other buyers from obtaining the assets. Accordingly, firms have incentives to choose a predation technology that destroys the assets, since the negative externalities exerted on rivals by using the prey's assets are then reduced (Proposition 2). Consequently, predation is not only socially harmful by limiting the number of competing firms, but also by reducing the total amount of productive assets in the industry.

In section 3.2, I address the McGee critique, i.e. that it cannot be rational to engage in predatory behavior, since an immediate merger is less costly. I will show that two frictions in the merger process weaken this argument in a multifirm setting. The first friction is the above mentioned free-riding problem, which stems from the fact that the buyer pays the costs of the partial monopolization. Predation, on the other hand, provides a way of sharing the costs of eliminating a rival. For instance, firms could share the costs of developing a new standard, or those of lobbying. Consequently, predation might be rational, since it might allow firms to circumvent the free-riding problem (Proposition 3). The second friction in the merger process is the bidding competition associated with obtaining the

\footnotetext{
${ }^{3}$ Note that this formalization differs from the one provided by Saloner, where predation was used for signaling.
} 
target firm. The threat of predation does not, in itself, affect the productivity of the target's assets for the potential buyers. The firms may therefore prefer to actually carry out the predation, since the bidding competition might then be reduced (Proposition 4).

In section 4, I explore the policy implications of the above mentioned findings in the context of different merger laws. ${ }^{4}$ Mergers creating or strengthening dominant positions are illegal according to the competition laws in most developed countries. Competition authorities typically implement these laws in a way which can roughly be described as "trying not to allow measured concentration to become too high". 5 This type of merger law will be referred to here as "restrictive merger law". If the target is failing, a merger leading to high concentration may nevertheless be accepted under the so-called "failing firm defense". This type of merger law will also be studied. More specifically, three merger law rules are considered. The first rule is a version of the restrictive merger law, according to which all mergers are assumed to be forbidden in the present case. This is referred to as the restrictive merger rule. The second and third rules are versions of the failing firm defense doctrine. The second rule is the existing US failing firm defense rule which contains a "least danger to competition" (LDC) condition stating that if more than one firm bid on the failing firm's assets, then the firm which constitutes the least danger to competition should be favored. The third rule is a modified version of the US failing firm defense rule, where no firm is favored in the acquisition process.

Saloner (1987) showed that the incentive for a potential monopolist to predate increases if he can acquire the prey after predation has occurred. He concluded that the market concentration might be increased by a failing firm defense clause. I show that a failing firm clause does not necessarily yield a tendency toward concentration in a multi-firm setting. In fact, I will illustrate that a restrictive merger policy may be counterproductive, in the sense that it leads to concentration. It may increase the incentives for predation by helping predators avoid a disadvantageous bidding competition for the prey after predation has occurred. Consequently, the incentive for predation for merger under a failing firm defense is limited, if the potential buyers compete to acquire the failing firm. On the other hand, the incentive for predation for merger under the US failing firm defense might be strong, since it allows mergers but limits the bidding competition by favoring small firms in the acquisition process.

\footnotetext{
${ }^{4}$ It is assumed that the competition authority cannot observe whether or not firms predate. This seems reasonable for several predation technologies: predatory pricing, development of standards etc.

${ }^{5}$ For instance, in the US, the Herfindahl-Hirschman Index (HHI) is used as a measure of concentration. The HHI is calculated by summing the squares of the individual market shares of all firms in the market.
} 
Section 5 contains some concluding remarks. Finally, most proof appears in the Appendix.

\section{The Model}

Three identical owners, 1,2 and 3 , are each endowed with the unit of assets necessary for producing a homogenous product. Initially, each owner operates a separate firm. There is also an owner $d$ who is identical to the other owners apart from being vulnerable to predation by owners 1, 2 and 3 . The source of the superiority in "strength" of the former is not formally modeled, but could be seen as resulting from e.g. large financial resources, strong R \& D departments, advantageous in lobbying, or superior information. ${ }^{6}$ The motivation behind this four firm set-up is that this is the fewest number of firms needed to derive the results in the paper. ${ }^{7}$

The interaction takes place over four periods. In period 1 , the firms may merge. In period 2, the firms compete in an oligopoly industry and generate profits. In this period, strong firms may predate in order to make the weak firm bankrupt. In the third period, the owners may again buy and sell assets. Finally, in period 4, firms compete in standard fashion. The motivation behind this four-period set-up will be clarified below.

\subsection{The merger formation}

In the merger formation stages, stages 1 and 3 , the owners of the firms decide whether to merge. The merger formation is modeled as in Kamien and Zang (1990), where owners simultaneously post bids for other firms and state an asking price for their own firm, and where the possible reallocation of assets is determined on basis of these bids and asks.

Let $N$ be the set of active owners in the industry. Each owner $j \in N$ announces a vector $\mathbf{b}_{j}=\left(b_{j}^{1}, b_{j}^{2}, \ldots, b_{j}^{n}\right) \in R^{n}$ of bids for each firm, where $n$ is the number of active owners. The bid $b_{j}^{j}$ is the $j$ th owner's bid or asking price for his own firm. Let $\mathbf{b}=\left(\mathbf{b}_{1}, \mathbf{b}_{2}, \ldots, \mathbf{b}_{n}\right)$ denote the $n \times n$ matrix of bids. Following the announcement of $\mathbf{b}$, each firm may be sold to one of the bidders at the bid price, or remain with its original owner. ${ }^{8}$

\footnotetext{
${ }^{6}$ For instance, Bolton and Scharfstein (1990) present a model with one financially strong and one financially weak firm. In this model a creditor offers the weak firm an optimal long-term contract. In order to provide managerial incentives, the creditor must punish a firm that makes a low profit in the first period by increasing the risk of terminating the credit. The weak firm is then vulnerable to predation by the strong firm.

${ }^{7}$ See the discussion at the end of Section 3 footnote 22 and footnote 25.

${ }^{8}$ It is assumed that owners cannot bid for the other firms on a contingency basis. According
} 
I will now describe a rule, named the laissez-faire rule, which allocates owner $i$ 's assets to any owner when there are no legal restrictions as to who may acquire which assets:

Definition 1. The laissez-faire rule allocates owner i's assets to the owner who posts the highest bid for the assets (including owner $i$ ). If there is more than one owner with such a bid, each such owner obtains the assets with equal probability.

Five possible types of market structures can arise at the end of a merger stage, where, within each category, firms with the same amount of productive assets make the same profits. These types of market structures are: the quadropoly, the triopoly, the symmetric duopoly, the asymmetric duopoly and the monopoly. For instance, asymmetric duopoly refers to all ownership structures where one owner possesses three units of assets, one owner possesses one unit of assets, and two owners have no assets. Let $\pi_{1}(2,1+d, 0,0)$ denote the profit of the firm possessing the number of assets written in the first entry in the vector, let $\pi_{2}(2,1+d, 0,0)$ denote the profit of the firm possessing the number of assets written in the second entry, etc. Note that, since predation may affect the productivity of owner d's assets, there may be a difference between the market structures where owner $d$ 's assets have been exposed to predation and those where they have not. To this end, let $\pi_{2}\left(2,1+d^{p}, 0,0\right)$ denote the profit of the firm possessing one unit of nonpredated assets and one unit of predated assets, written in the second entry in the symmetric duopoly, etc. The superscript $p$ denotes that owner $d$ 's assets have been exposed to predation.

The merger formation game is solved for Nash equilibria in undominated pure strategies.

A central feature of this model is how changes in the ownership of owner $d$ 's assets affect the strong firms' profits. The profit for firm $i$, when owner $j$ obtains owner $d$ 's assets for a given initial market structure is denoted $\pi_{i d}^{j}$, and the profit for firm $i$ when owner $d$ 's assets exit is denoted $\pi_{i d}^{e}$. Thus, at the outset, $\pi_{1 d}^{2}=\pi_{1}(1,1+d, 1,0)$ and $\pi_{1 d}^{e}=\pi_{1}(1,1,1,0)$.

I make the following two assumptions about how profits are affected by asset transfers:

Assumption 1 When firms merge, the profits of firms outside the merger increase.

This assumption is fulfilled in most oligopoly models as long as the merger does not create strong variable cost synergies.

to Kamien and Zang (1991) bidding on a contingency basis would appear to be a direct violation of the U.S. antitrust laws. 
The second assumption concerns how profits are affected when a firm increases its number of assets, without any other firm in the industry decreasing its number of assets. Note that in the model, assets cannot be imported from outside. However, the assumption relates to a comparison between situations where assets exit or do not exit.

Assumption 2 When a firm increases its ownership of otherwise exiting assets the industry, its profit increases, and its rivals' profits decrease.

This assumption is fulfilled in most oligopoly models where an increased capital stock decreases marginal costs. ${ }^{9}$

Moreover, it is assumed that a buyer's profit is at least as high when he obtains owner d's non-predated assets as when he obtains owner $d$ 's predated assets, i.e. $\pi_{i d}^{i} \geq \pi_{i d}^{i p}$, where $p$ denotes that owner $d$ 's assets have been exposed to predation. It is also assumed that the negative externalities on rivals are at least as strong for non-predated as for predated assets, $\pi_{j d}^{i} \leq \pi_{j d}^{i p}$.

A central feature of this study is how a redistribution of owner $k$ 's assets to owner $j$ and not to owner $l$ affects owner $i$ 's profit. This valuation for owner $i$, $v_{i k}^{j l}$, is defined

Definition 2. $v_{i k}^{j l} \equiv \pi_{i k}^{j}-\pi_{i k}^{l}$

This valuation is determined by two components. One is the profit made by owner $i$ when firm $j$ has acquired firm $k$ 's assets, and the second is the profit made by owner $i$ when owner $l$ has acquired the assets. Note that $v_{i k}^{i l}$ is the gain for owner $i$ of obtaining the assets given that owner $l$ will otherwise obtain them. Finally, let $v_{i d^{p}}^{j l}$ denote that owner $d$ 's assets have been exposed to predation.

\subsection{The oligopoly interaction}

In the oligopoly interaction stages, stages 2 and 4, each owner uses his assets in a separate firm. The strong firms have the option to predate. The predation technology is intentionally left unspecified. It is assumed that firm $d$ is bankrupt if its profit is below a threshold value $z$. One can distinguish between two kinds of models that are compatible with this assumption. The first is asymmetric information models, where the players' beliefs are affected by predation and thus, predation does not affect the "real" productivity of the assets. For instance, Bolton and Scharfstein (1990) present a model with one financially strong and one financially weak firm. In this model a creditor offers the financially weak

\footnotetext{
${ }^{9}$ See the paper by Farrell and Shapiro (1990) for an extensive study of the effects of asset transfers in a Cournot model.
} 
firm an optimal long-term contract. In order to provide managerial incentives, the creditor must punish a firm that makes a low profit in the first period by increasing the risk of terminating credit. The weak firm is then vulnerable to predation by the strong firm. The other kind of models consists of the models where predation affects "real" productivity. Salop and Scheffman (1983) present a model where a predator can raise his rivals' costs by using product standardization and advertising expenditures, for example.

Predation is costly in the short run. Let $x_{i}$ denote firm $i$ 's, $i \neq d$, costs, where $x=\sum_{i} x_{i}$. To simplify the analysis, I assume that predation only affects the prey when the total costs of investing in predation are at least as high as $\bar{x} .{ }^{10}$ In this case, firm $d$ 's profit falls to the threshold value $z .{ }^{11}$ The profit for a strong firm $i$, firm 1 say, when predating in the quadropoly is $\pi_{1}(1,1,1, d)-x_{1}$, and the profit for the prey is denoted $\pi_{4}^{\prime}(1,1,1, d)$. The profits when not predating are $\pi_{1}(1,1,1, d)$ and $\pi_{4}(1,1,1, d)$, respectively, etc. It is assumed that predation by one strong firm does not affect the profit of other strong firms. This simplifies the notation and the analysis, but is of no fundamental importance. ${ }^{12}$

\section{Incentives for predation and merger}

This section analyzes the firms' incentives for predation and mergers in situations where there are no restrictions on mergers. Section 3.1 analyzes the strong firms' incentives for predation for merger. Section 3.2 shows that firms might prefer to predate despite the option to merge immediately.

\subsection{Predation for mergers}

The first issue is to show that the option to predate increases the incentive for mergers in a multi-firm setting. For this purpose, I restrict the analysis to periods 2, 3 and 4, so that I can focus on how predation affects the incentive for mergers. Thus, I consider a reduced version of the full model, where no mergers have taken place in period 1 . In section 3.2 , I analyze the full model.

\footnotetext{
${ }^{10} \mathrm{It}$ is possible that not only the total amount of $x$ will be of importance, but also the distribution of $x_{i}$ s. However, since I restrict the analysis to symmetric equilibria, this will be of no importance here.

${ }^{11}$ This assumption is made in order to focus on the trade-off between non-predation and predation for bankruptcy. In a more general setting it is possible that the predators might prefer to predate in such a way that the prey's profit falls below $z$.

${ }^{12}$ If there are externalities on other strong firms, these could be either positive or negative. This implies, as will be argued below, that there might be over- as well as under-provision of entry deterrence from the perspective of the strong firms, depending on the nature of the technology. However, what is important for the results is that a sufficiently large portion of the costs of predation be shared.
} 
Period 4. This is the last period and hence the firms have no incentive to predate. They will thus compete in standard fashion and generate profits.

Period 3. There are only two possible situations to consider in period 3 . We either have a quadropoly where firm $\mathrm{d}$ is bankrupt, or a quadropoly where it is not.

Let us start with the situation where firm $d$ is not bankrupt. Using the approach of Kamien and Zang, the following conditions are sufficient for no mergers to occur in equilibrium in period $3:^{13}$

$$
\begin{aligned}
& \text { C1 (i) } \pi_{1}(4,0,0,0)-\pi_{1}(1,1,1,1)<3 \pi_{2}(3,1,0,0), \\
& \text { (ii) } \pi_{1}(3,1,0,0)-\pi_{1}(1,1,1,1)<2 \pi_{2}(2,1,1,0) \text {, } \\
& \text { (iii) } \pi_{1}(2,2,0,0)-\pi_{1}(1,2,1,0)<\pi_{2}(2,1,1,0) \text {, and } \\
& \text { (iv) } \pi_{1}(2,1,1,0)-\pi_{1}(1,1,1,1)<\pi_{2}(1,1,1,1)
\end{aligned}
$$

Thus, we have the following result:

Lemma 1. If firm $d$ is not bankrupt and $C 1$ holds in period 3, then the quadropoly structure is the unique Nash equilibrium.

Proof. See Appendix.

The intuition for the results are as follows. First note that an unmerged equilibrium always exists. To see this, consider the situation where all firms post an asking price at $\pi_{1}(4,0,0,0)+\varepsilon$, say, and a bid at $\pi_{1}(1,1,1,1)-\varepsilon$, say. This is a Nash equilibrium, since no owner will become better-off by lowering his asking price and becoming a seller, or by raising his bid and becoming a buyer, or both.

Second, in order to see why C1 is a sufficient condition for no merger to occur, consider the monopoly structure as an equilibrium candidate. Let owner 1 be the buyer. Then his profit is $\pi_{1}(4,0,0,0)$, and $\pi_{1}(1,1,1,1)$ will be his profit if he lowers his bid to the three sellers and becomes a non-buyer when all other firms maintain their ownership. This is the lowest profit owner 1 can make, since his profit will be higher in any other more concentrated market structure, according to A2. Owner 1 is thus unwilling to pay the three sellers more than the total of $\pi_{1}(4,0,0,0)-\pi_{1}(1,1,1,1)$. Consider next one of the three sellers, say the second owner. If he unilaterally deviates and raises his asking price above the first owner's bid, his firm will not be bought, and he will realize a profit of $\pi_{2}(3,1,0,0)$. It follows that the first owner has to pay each seller at least $\pi_{2}(3,1,0,0)$ or at least $3 \pi_{2}(3,1,0,0)$ to all of them. Consequently, such an equilibrium is impossible if $\pi_{1}(4,0,0,0)-\pi_{1}(1,1,1,1)<3 \pi_{2}(3,1,0,0)$. Thus, if (i) in C1 holds, there is no

\footnotetext{
${ }^{13}$ Note that the condition is constructed with owner 1 as the buyer. implies that the conditions are identical for owners 2, 3 and 4 as buyers.

However, symmetry
} 
merger for monopoly in equilibrium. ${ }^{14}$ The same reasoning applies to the other equilibria involving at least one merger. ${ }^{15}$

Thus, mergers do not occur due to the free-riding problem: it is more profitable to be outside a merger. Consider now the situation where firm $d$ is bankrupt. The merger formation is now conducted under the restriction that owner $d$ must sell his assets. ${ }^{16}$ In order to include this restriction in the merger formation model, the allocation rule is modified. The bankruptcy rule, denoted $S^{b}(i)$, is identical to the laissez-faire rule, apart from the fact that owner $d$ can neither make a bid on other firms nor put an asking price on its own firm. The reason is that firm $d$ 's assets are now assumed to be in the hands of a trustee who will sell the assets to the bidder with the highest bid. ${ }^{17}$ More precisely, the bankruptcy rule is defined as follows:

Definition 3. The bankruptcy rule is identical to the laissez-faire rule, except that owner $d$ can neither make an ask on its own assets nor a bid on the other owners' assets.

In order to focus on the elimination of the weak firm only, I state the following sufficient condition for no mergers to occur between the strong firms in equilibrium:

C2 (i) $\pi_{1}\left(3+d^{p}, 0,0,0\right)-\pi_{1}\left(1,1+d^{p}, 1,0\right)<2 \pi_{2}\left(2+d^{p}, 1,0,0\right)$,

(ii) $\pi_{1}\left(2+d^{p}, 1,0,0\right)-\pi_{1}\left(1,1+d^{p}, 1,0\right)<\pi_{2}\left(1+d^{p}, 1,1,0\right)$, and

(iii) $\pi_{1}\left(2,1+d^{p}, 0,0\right)-\pi_{1}\left(1,1+d^{p}, 1,0\right)<\pi_{2}\left(1,1,1+d^{p}, 0\right)$

In Lemma 2, it is shown that under $\mathrm{C} 2$, in equilibrium, no mergers occur between the equity firms, but that a merger involving the weak firm takes place:

Lemma 2. If firm $d$ is bankrupt and $\mathrm{C} 2$ holds in period 3, then the market structure is a triopoly in all symmetric Nash equilibria and an owner $i \neq d$ obtains $d$ 's assets for a price equal to owner $j$ 's, $j \neq i, d$, valuation of obtaining d's assets instead of owner $i$ obtaining them, $v_{j d^{p}}^{j i}$.

\footnotetext{
${ }^{14}$ The proof of Lemma 1 builds on proof provided by Kamien and Zang (1990).

${ }^{15} \mathrm{In}$ order to show that $\mathrm{C} 1$ and similar conditions which will be used in the analysis are consistent, I use a model - denoted "the linear model"- in which inverse demand is $p=1-Q$, and where each firm's costs are zero. Proof of the statements for the linear model is provided in the Appendix.

${ }^{16}$ According to, for instance, Chapter 11 of US bankruptcy law, a bankrupt firm has a chance to re-organize and continue its operation. However, it is assumed here that the bankrupt firm does not successfully re-organize. This assumption could be supported by the Bolton and Scharfstein model, for example, since in that model a weak firm cannot refinance its operation after generating low profits in a previous period.

${ }^{17}$ Note that this imply that the seller cannot state a reservation price.
} 
Proof. See Appendix.

The intuition for the results are as follows. Consider the equilibrium candidate, $b^{d *}: b_{1}^{d *}=b_{2}^{d *}=b_{3}^{d *}$. Thus, owner 1,2 , or 3 acquires owner $d$ 's assets. Let $i \neq d$ and $j \neq i, d$. Then, note that $b_{i}^{d}>v_{i d^{p}}^{i j}=v_{j d^{p}}^{j i}$ is not an equilibrium, since no owner will obtain the asset for a price above his maximum valuation of obtaining the assets. If $b_{i}^{d}<v_{j d^{p}}^{j i}$, owner $j$ benefits from deviating to $b_{j}^{d}=b_{i}^{d *}+\varepsilon$, since he will then obtain the assets at a price lower than his valuation of obtaining them. Let now $b_{i}^{d *}=b_{j}^{d *}=v_{i d^{p}}^{i j}$ and assume that owner $i$ obtains the assets. No owner then has an incentive to deviate. Finally, note that the quadropoly is not an equilibrium. All owners must then have posted negative bids for owner $d$ 's assets. But owner $i$ then has an incentive to deviate to $b_{i}=0$, since $v_{i d^{p}}^{i e} \geq 0$ by Assumption 2.

The buyer's net profit over periods 3 and 4 , given that firm $d$ is bankrupt, is the profit of the merged entity in period 4 minus the acquisition price in period 3. Note that if the outside firm's profit decreases, the price of the prey's assets increases with the same amount since, according to Lemma 2, the price of the prey is determined by the outside firm's willingness to pay. Since the outside firm's willingness to pay increases with the same amount as its profit outside the merger decreases, the price accordingly changes with the same amount. Thus, the stronger negative externalities exerted by the use of the bankrupt firm's assets, the lower is the net profit for the merged entity. Note also that the profits for a firm that does not obtain the assets are the same as for the buyer since, as shown by Lemma 2, the price of the prey is equal to the non-buyers' willingness to pay. Consequently, the strong firms are indifferent to buying or not buying. Thus, in a situation where the target firm is bankrupt, the acquisition price will be so low that the free-riding problem is absent.

Period 2. In the remainder of this section, it is assumed that $\mathrm{C} 1$ and $\mathrm{C} 2$ hold. Thus, there will be no merger in period 3 if firm $d$ is not bankrupt, and if firm $d$ is bankrupt there will be a merger between one of the strong firms and firm $d$. In period 2, the strong firms have the option to predate. Predation has the characteristic of a public good in the sense that if firm $i$ predates, all "strong" firms benefit. A free-riding problem might thus arise, since only firm $i$ pays the costs. The following Lemma characterizes the symmetric Nash equilibria:

Lemma 3. (i) If it is profitable for the strong firms as a group to predate, then $x_{i}^{*}=\frac{\bar{x}}{n-1}, \forall i \neq d$ and $x_{i}^{* *}=0, \forall i \neq d$ are the only symmetric Nash equilibria. Moreover, $x_{i}^{*}$ Pareto dominates $x_{i}^{* *}$ for the group of strong firms. (ii) If it is not profitable for the group of strong firms to predate, then $x_{i}^{*}=0, \forall i \neq d$ is the only symmetric Nash equilibrium.

Proof. See Appendix. 
I restrict the analysis to the symmetric Pareto dominating equilibrium in provision of predation. This assumption seems defendable on at least three grounds. First, the restriction seems reasonable for predation technologies such as development of standards and lobbying, where it is likely that the strong firms are able to communicate. It then seems plausible that the strong firms can settle for a Nash equilibrium which is not Pareto-dominated by any other Nash equilibrium. Second, in the literature on multi-firm entry deterrence, it has been shown that there might be over- as well as under-provision of entry deterrence from the perspective of the strong firms, depending on the nature of the technology. ${ }^{18}$ It is thus probable that the free-riding problem might also be avoided in situations where firms cannot communicate, since multi-firm predation in this set-up resembles multi-firm entry deterrence. ${ }^{19}$ Finally, it is not the equal sharing, but rather that a sufficiently large share of the costs of predation is shared, which is important for the results in this paper. ${ }^{20}$

Let us now determine when a strong firm will predate. Recall that the profits over periods 3 and 4 are equal for all strong firms, irrespective of whether they are buyers or not. Thus, it is sufficient to look at the incentive for one of the strong firms to predate, for example firm 1. Let us, without loss of generality, assume that firm 1 is the firm that will merge with firm $d$ in period 3 if firm $d$ is bankrupt. Firm 1's total profit from predation consists of two parts; its profit in period 2 plus its profit as a merged entity in period 4 minus the price paid for the prey in period 3, i.e. $\pi_{1}(1,1,1,1)-\frac{\bar{x}}{3}+\pi_{1}\left(1+d^{p}, 1,1,0\right)-\left(\pi_{2}\left(1,1+d^{p}, 1,0\right)-\pi_{2}\left(1+d^{p}, 1,1,0\right)\right) .{ }^{21}$ If firm 1 does not predate, it makes a non-predation quadropoly profit in period 2 and in period 4 , i.e. $\pi_{1}(1,1,1, d)+\pi_{1}(1,1,1, d)$. Recall that $\mathrm{C} 1$ is assumed to hold and consequently Lemma 1 applies. Thus, there are no mergers in period 3 if firm 1 does not predate. This implies that firm 1 predates only when the following condition is fulfilled:

C3 $\pi_{1}(1,1,1, d)-\frac{\bar{x}}{3}+\pi_{1}\left(1+d^{p}, 1,1,0\right)-\left(\pi_{2}\left(1,1+d^{p}, 1,0\right)-\pi_{2}\left(1+d^{p}, 1,1,0\right)\right)>$ $2 \pi_{1}(1,1,1, d)$

\footnotetext{
${ }^{18}$ See for instance Appelbaum and Weber (1992), Gilbert and Vives (1986), and Kovenock and Roy (1995).

${ }^{19}$ The issue of multi-firm predation has only recently been addressed, Nolan (1998). The author shows that predation is an equilibrium strategy for some parameter values. However, he also show that there exist a free-riding problem for some parameter values. Note also that multi-firm predation has been considered by the Courts. In the case Matsushima v. Zenith, several Japanese firms were alleged to jointly predate against US firms in the television receiver industry. See Kwoka and White (1994).

${ }^{20}$ Note that predation is an equilibrium outcome in Nolan (1998) without the symmetry assumption.

${ }^{21}$ Recall that firm 1 will merge with firm $d$ and no other merger will take place in period 3 according to Lemma 2 , since $\mathrm{C} 2$ is assumed to hold.
} 
We thus have the following result

Lemma 4. If $C 1$ and $C 2$ hold in period 2, the unique symmetric Nash equilibrium for predation is $x_{i}^{*}=\frac{\bar{x}}{3}, \forall i \neq d$ if $C 3$ holds, and $x_{i}^{* *}=0, \forall i \neq d$ if C3 does not hold.

If we interpret the situation where the cost of predation is infinite, as a situation where predation is not an option, it can be shown that a symmetric equilibrium exists where the option of predation increases the incentive for merger.

Proposition 1. Payoff configurations exist such that (i) if predation is not an option, no symmetric subgame perfect Nash equilibrium involves a merger; and (ii) if predation is an option, predation occurs in period 2 in all symmetric subgame perfect Nash equilibria, and is followed by a merger between one of the strong firms and the weak firm in period 3 .

Proof. See Appendix.

The option to predate increases the incentive for merger, since predation weakens the prey's bargaining position. Thus, firms may overcome the free-riding problem associated with mergers by sharing the costs of making the rival bankrupt, and by changing the acquisition situation in favor of the buyer. Recall that if no predation takes place, the buyer must pay a high price for the target, since the target's bargaining position is strong. In this situation, it is thus better to be outside the merger. But, when predation is a possibility, the target's bargaining position is weak, and the firms are indifferent between buying or not.

\subsubsection{The bidding competition and the choice of predation technology}

As shown above, the stronger the negative externalities exerted by the prey's assets, the higher price the firms are willing to pay for them. But, the buyer's net profit does not increase with the same amount in relation to the initial situation, absent predation. This is due to the fact that the buyer then mainly pays a high price in order to prevent other buyers from using the assets and less to increase his profit relative to the initial situation. Thus, the incentive for predation for merger depends on the extent to which predation affects the productivity of the prey's assets when employed in the strong firms.

From Assumption 2, we have that a potential buyer's gross profit increases if it obtains owner $d$ 's non-predated assets, i.e., $\pi_{i d}^{i}>\pi_{i d}^{e}$, and the rivals' profits decrease, i.e. $\pi_{j d}^{i}<\pi_{j d}^{e}$. Let us say that the firms use a non-destructive predation technology where predation does not affect the productivity of the prey's assets for the buyer, i.e. $\pi_{i d}^{i}=\pi_{i d}^{i p}$ and $\pi_{j d}^{i}=\pi_{j d}^{i p}$. This kind of predation is compatible 
with the asymmetric information models discussed above, where predation serves the purpose of signaling. For instance, if the assets are physical capital and the predation technology is pricing, then predation is not likely to change the effect of the capital on cost savings. According to the above reasoning, firms have limited incentives for predation for mergers when they use a non-destructive predation technology, since the bidding competition after predation might have considerable negative effects.

There are, however, several examples of predation technologies that can reduce the usefulness of the assets. For instance, firms may advertise heavily in order to destroy the appeal of the brand name of the prey. Or, firms may lobby for restrictions on trade, safety or health issues, and thus reduce the usefulness of the assets of the prey in production. In order to capture these situations, we denote the other extreme where $\pi_{i d}^{i p}=\pi_{i d}^{e}$ and $\pi_{j d}^{i p}=\pi_{j d}^{e}$, as one where firms use a destructive predation technology, i.e. a technology making the bankrupt firm's assets useless. Let us now assume that the strong firms could choose either the non-destructive predation technology, or the destructive predation technology. The following Proposition then shows that the firms have an incentive to choose the destructive predation technology: ${ }^{22}$

Proposition 2. When $C 1$ and $C 2$ hold, and if the strong firms must choose between the non-destructive and the destructive predation technology, they choose the destructive one.

Proof. See Appendix.

The bidding competition is most harmful to predators when the use of the prey's assets exerts strong negative externalities on rivals, since the potential buyers are then willing to pay a high price for the prey in order to prevent other buyers from obtaining the assets. Accordingly, firms have incentives to choose a predation technology that destroys the assets, since the negative externalities exerted on rivals by using the prey's assets are then reduced. ${ }^{23}$ Consequently, predation is not only socially harmful by limiting the number of competing firms, but also by reducing the total amount of productive assets in the industry.

The motivation behind the four firm set-up is that at least three strong firms are needed to satisfy condition $\mathrm{C} 2$ in the linear model. With only two strong firms, $\mathrm{C} 2$ is violated, resulting in an equilibrium with a merger to monopoly. For instance, it is straightforward to verify that the following configuration is then an equilibrium: $b_{1}^{1}=\frac{1}{4}+\varepsilon, b_{1}^{2}=\frac{1}{8}, b_{1}^{d}=0, b_{2}^{1}=0, b_{2}^{2}=\frac{1}{8}-\varepsilon, b_{2}^{d}=0$. Since there always

\footnotetext{
${ }^{22}$ It is assumed that the strong firms can coordinate on the predation technology that is most advantageous for the group of strong firms.

${ }^{23}$ Note that if the firms are asymmetric it might be the case that the buyer may generate a surplus in the auction, and thus may prefer a non-destructive predation technology.
} 
exists an unmerged equilibrium, if condition $\mathrm{C} 2$ does not hold, there are multiple equilibria. Thus, three strong firms is the minimal number of firms sufficient to avoid multiple equilibria in the linear model. However, it is straightforward to show that conditions $\mathrm{C} 1$ and $\mathrm{C} 2$ can be satisfied with a larger number of firms and in other oligopoly models. Moreover, condition C3 can be generalized to the $n$-strong-firm case: $\pi_{2}\left(1+d^{p}, 1, \ldots, n, 0\right)-\pi_{1}(1, \ldots, n, d)>\frac{\bar{x}}{n}$. Since the left hand side of this expression is positive for an arbitrary $n$ in many oligopoly models and the right hand side is decreasing in $n$, C3 will hold also in other oligopoly models and in models with a larger number of firms. Since C1, C2 and C3 is a jointly sufficient condition for our results, these results generalize to situations with a larger number of firms and to other oligopoly models.

\subsection{Threat of predation, predation and mergers}

The results derived in Section 3.1 might be subject to the criticism raised by McGee $(1958,1980)$, i.e. that predation is not rational, since an immediate merger is more advantageous. ${ }^{24}$ In order to examine this argument within the present framework I include period 1, where firms have the option to merge.

\subsubsection{Predation to overcome the free-riding problem}

In this section, I show that firms might predate in equilibrium in the linear model, since predation helps them overcome the free-riding problem. In the linear model, the single-firm profit in an $r$-firm industry absent predation is given by $\pi_{i}(r)=$ $\frac{1}{(r+1)^{2}}$. Note that the predation technology is destructive in the linear model, in the sense that if firm $d$ is bankrupt, its assets will be of no value for the predators. It is therefore assumed that firm $d$ exits if bankrupt. Let us now turn to the analysis.

Period 4 The remaining firms will not predate, since this is the last period. The single-firm profit in an $r$-firm industry is thus given by $\pi_{i}(r)=\frac{1}{(r+1)^{2}}$.

Period 3 There are four different market structures to consider, since the firms may have merged in period 1.

Monopoly. It follows directly that no merger will take place in this situation.

\footnotetext{
${ }^{24}$ It follows that the argument is not valid when (i) only mergers with bankrupt firms are allowed, as is the case under the failing firm defense, and (ii) predation serves the purpose of signaling, since predation must be carried out to affect the merger incentives in these situations.
} 
Duopoly. If there are two strong firms in the industry, it is assumed that these will merge and share the profits equally, since the monopoly profit is larger than two duopoly profits, i.e. $\pi_{i}(1)=\frac{1}{(2)^{2}}>2 \pi_{i}(2)=2 \frac{1}{(3)^{2}}$.

If there is one strong firm and firm $d$ is bankrupt, firm $d$ exits.

Triopoly. If there are three strong firms, there are no mergers, since $\pi_{i}(1)-$ $\pi_{i}(3)=\frac{1}{(2)^{2}}-\frac{1}{(4)^{2}}<2 \pi_{i}(2)=\frac{2}{(3)^{2}}$ and $\pi_{i}(2)-\pi_{i}(3)=\frac{1}{(3)^{2}}-\frac{1}{(4)^{2}}<\pi_{i}(3)=\frac{1}{(4)^{2}}$. This follows from the same reasoning as was applied in the derivation of $\mathrm{C} 1$.

If there are two strong firms and one bankrupt firm, firm $d$ exits. It then follows that the two strong firms merge with the same motivation as the one presented in the duopoly situation above.

Quadropoly. When there are three strong firms and firm $d$ is not bankrupt, there are no mergers, since $\pi_{i}(1)-\pi_{i}(4)=\frac{1}{(2)^{2}}-\frac{1}{(4)^{2}}<3 \pi_{i}(2)=\frac{3}{(3)^{2}}, \pi_{i}(2)-\pi_{i}(4)=$ $\frac{1}{(3)^{2}}-\frac{1}{(5)^{2}}<2 \pi_{i}(3)=\frac{2}{(4)^{2}}$, and $\pi_{i}(3)-\pi_{i}(4)=\frac{1}{(4)^{2}}-\frac{1}{(5)^{2}}<\pi_{i}(4)=\frac{2}{(5)^{2}}$.

If there are three strong firms and one bankrupt firm, firm $d$ exits, and there are no mergers between the strong firms, with the same motivation as the one presented in the triopoly situation above.

Period 2 There are four different market structures to consider, since firms may have merged in period 1.

Monopoly. The monopolist does not predate and consequently its profits over periods 2 and 4 are $\pi_{i}(1)+\pi_{i}(1)$.

Duopoly. If there are two strong firms, these cannot predate and their profits over periods 2 and 4 are $\pi_{i}(2)+\frac{1}{2} \pi_{i}(1)$, since the two strong firms merge in period 3.

If there is one strong firm and firm $d$, the strong firm's profits when predating are $\pi_{i}(2)-\bar{x}+\pi_{i}(1)$, since firm $d$ will exit in period 3 , if it is bankrupt. If the strong firm does not predate, it will merge with firm $d$ on equal terms in period 3 . The profits when not predating are thus $\pi_{i}(2)+\frac{1}{2} \pi_{i}(1)$. Consequently, the strong firm predates iff $\bar{x}<0.125$.

Triopoly. When there are three strong firms, they cannot predate, and their profits over periods 2 and 4 are $\pi_{i}(3)+\pi_{i}(3)$, since the three strong firms will not merge in period 3 .

If there are two strong firms and firm $d$, the strong firms' profits when predating are $\pi_{i}(3)-\frac{\bar{x}}{2}+\frac{1}{2} \pi_{i}(1)$, since firm $d$ exits in period 3 if it is bankrupt and the two strong firms will merge on equal terms. If the strong firms do not predate, there will be no merger in period 3 and the profits of not predating are thus $\pi_{i}(3)+\pi_{i}(3)$. Consequently, the strong firms predate iff $\bar{x}<0.125$. 
Quadropoly. The strong firms' profits when predating are $\pi_{i}(4)-\frac{\bar{x}}{3}+\pi_{i}(3)$, since firm $d$ exits in period 3 if it is bankrupt, and there are no mergers between the strong firms. If the strong firms do not predate, there will be no exit and no merger in period 3, and thus the profits over periods 2 and 4 for the strong firms when not predating are $\pi_{i}(4)+\pi_{i}(4)$. Thus, they predate iff $\bar{x}<0.0675$.

Period 1 I will now show that firms predate the prey in period 2 despite the option to merge with it in period 1 . To this end, consider any equilibrium involving a merger in period 1. $\pi_{1}^{\prime}$ denotes the buyer's, say the first owner, profits over periods 2 and 4 , and $\pi_{1}^{\prime \prime}$ are his profits over both periods if he instead lowers his bid to the sellers below their asking prices. The first owner is unwilling to pay the sellers more than $\pi_{1}^{\prime}-\pi_{1}^{\prime \prime}$. Consider next any seller, say the second owner. If he deviates and raises his asking price above the first owner's bid, he will not be bought, and will realize a profit over periods 2 and 4 of $\pi_{2}^{\prime \prime \prime}$. It follows that the first owner has to pay each seller at least $\pi_{2}^{\prime \prime \prime}$. Let us assume that $\bar{x}<0.0675$. This implies that there will be predation in any market structure in period 2 . Then note that there is no merger for monopoly, if (i) $\frac{2}{4}-\left(\frac{1}{25}-\frac{\bar{x}}{3}+\frac{1}{16}\right)-2\left(\frac{1}{9}+\frac{1}{2}\left(\frac{1}{4}\right)\right)-z<0$ according to the reasoning above. To see this, note that the profit for owner 1 of buying is the monopoly profit over periods 2 and 4 , i.e. $\pi_{1}^{\prime}=2 \pi_{i}(1)=\frac{2}{4}$, the profit when not buying is the quadropoly profit minus one third of the predation cost, which will occur in equilibrium, plus the triopoly profit in period 4; the profit for each of the two strong firms when deviating is the duopoly profit in period 2 and half the monopoly profit in period 4 , since the two remaining firms will in equilibrium merge into a monopoly in period 3; i.e. $\pi_{2}^{\prime \prime \prime}=\pi_{i}(2)+\frac{1}{2} \pi_{i}(1)$; the profit for firm $d$ when deviating is the prey's profit in period 2 , since the strong firms will predate in equilibrium; i.e. $\pi_{d}^{\prime \prime \prime}=z$. The same reasoning applies to all market structures involving a merger. It follows that there is no merger for (ii) asymmetric duopoly with a merger involving firm $d$, if $\frac{1}{9}+\frac{1}{2}\left(\frac{1}{4}\right)-\left(\frac{1}{25}-\right.$ $\left.\frac{\bar{x}}{3}+\frac{1}{16}\right)-\frac{2}{16}-z<0$, (iii) asymmetric duopoly with a merger not involving firm $d$, if $\frac{1}{9}-\bar{x}+\frac{1}{4}-\left(\frac{1}{25}-\frac{\bar{x}}{3}+\frac{1}{16}\right)-2\left(\frac{1}{16}-\frac{\bar{x}}{2}+\frac{1}{2}\left(\frac{1}{4}\right)\right)<0$, (iv) symmetric duopoly, if $\frac{1}{9}+\frac{1}{2}\left(\frac{1}{4}\right)-\frac{2}{16}-\frac{2}{16}<0$, ( $\mathrm{v}$ ) triopoly with a merger not involving firm $d$, if $\frac{1}{16}-\frac{\bar{x}}{2}+\frac{1}{2} \frac{1}{4}-\left(\frac{1}{25}-\frac{\bar{x}}{3}+\frac{1}{16}\right)-\left(\frac{1}{25}-\frac{\bar{x}}{3}+\frac{1}{16}\right)<0$, and $(\mathrm{v})$ triopoly with a merger involving firm $d$, if $\frac{1}{16}+\frac{1}{16}-\left(\frac{1}{25}-\frac{\bar{x}}{3}+\frac{1}{16}\right)-z<0$

It then follows that parameter values exist where no mergers take place in period 1, but predation occurs in period 2, as shown in the following Proposition:

Proposition 3. If $\bar{x}=0.015$ and if $z>0.0275$, in the linear model, there are no mergers in period 1 but predation in period 2 followed by exit of firm $d$ in period 3 , in all symmetric subgame perfect Nash equilibria. 
The Proposition shows that McGee's argument is not necessarily true in a multi-firm setting. Despite the fact that the threat of predation decreases firm $d$ 's reservation price, the price of the target might still be too high for the buyer. ${ }^{25}$ A free-riding problem might therefore exist, i.e., all gains from the merger are not captured by the merging parties. But as argued above, predation provides a way of sharing the costs and gains of eliminating a rival. Thus McGee's argument is not correct in a multi-firm setting, since predation helps firms circumvent the free-riding problem associated with eliminating a rival by merger.

But, if the prey's bargaining position is much weakened by predation, i.e. $z=$ 0 , is McGee's argument then not valid? The answer is "no", since an equilibrium always exists in period 1 where no mergers take place. To see this, consider the situation where all firms post an asking price at $2 \pi_{i}^{M}+\varepsilon$, say, and a bid at $z-\varepsilon$, say. It follows directly that this is a Nash equilibrium since no owner can become better-off by either lowering his asking price and becoming a seller, or by raising his bids and becoming a buyer, or both. However, other equilibria exist in this situation. In the next section, I take a closer look at the situation where the bargaining position for the prey is totally destroyed.

\subsubsection{Predation to reduce the negative effects of bidding competition}

In this section, it is shown that predation might occur in equilibrium, since predation limits the negative effects of the bidding competition of the prey. To focus on the merger with the prey, I make the following assumption

Assumption 3 There are no mergers between the strong firms in period 1 and no mergers between non-bankrupt firms in period 3 .

The following result can then be derived:

Proposition 4. If Assumption 3 is fulfilled, if the strong firms predate in period 2 , and if $z=0$, two subgame perfect symmetric Nash equilibria exist: (i) the triopoly structure where owner $i \neq d$ obtains $d$ 's assets at a price equal to owner $j$ 's, $j \neq i, d$, valuation of obtaining d's assets instead of owner $i, v_{j d}^{j i}$, in period 1 ; and (ii) the triopoly structure, where no merger occurs in period 1, predation occurs in period 2, and firm $i \neq d$ obtains d's assets at a price equal to firm j's, $j \neq i, d$, valuation of obtaining $d$ 's assets instead of owner $i, v_{j d^{p}}^{j i}$, in period 3 .

\footnotetext{
${ }^{25}$ Note that predation decreases the prey's profit, since $z=0.0275<0.04=\pi_{i}(4)$. A positive reservation price, $z$, is compatible with the asymmetric information models provided by, for instance, Bolton and Scharfstein, and Saloner.
} 
Thus, two equilibria exist. In the first, firms merge in period 1, and this equilibrium is referred to as the immediate merger. In the second, firms do not merge in period 1 , but predate in period 2 and merge in period 3 . This equilibrium is referred to as the delayed merger. By using symmetry, we have that firm 1's profit when merging immediately is given by $2 \pi_{2}(1+d, 1,1,0)$, and the profit when merging in period 3 is given by $\pi_{1}(1,1,1, d)-\frac{\bar{x}}{3}+\pi_{2}\left(1+d^{p}, 1,1,0\right)$. We see that the cost of predation is $\pi_{2}(1+d, 1,1,0)-\left(\pi_{1}(1,1,1,1)-\frac{\bar{x}}{3}\right)$. The gain from predation is $\pi_{2}\left(1+d^{p}, 1,1,0\right)-\pi_{2}(1+d, 1,1,0)$, which captures the fact that the gain from predation comes from limiting the strength of negative externalities of the prey's assets. Let $x^{p}$ denote the costs of predation at which the strong firms are indifferent between the two equilibria. If $\bar{x}>x^{p}$, the strong firms are thus better-off merging in period 1. The immediate merger thus Pareto dominates the delayed merger for $\bar{x}>x^{p}$, since owner $d$ prefers to be acquired irrespective of whether $\bar{x}>x^{p}$ or not.

On the other hand, if $\bar{x}<x^{p}$, no equilibrium Pareto dominates the other, since the strong firms then prefer the delayed merger. Thus predation must be carried out to limit the negative effects of the bidding competition among the potential buyers. If the costs of predation are sufficiently low, the firms benefit from taking these costs. Consequently, the strong firms will be better-off if they can agree not to bid on the weak firm in period 1 . This might be accomplished if the strong firms create a bidding ring based on a threat to punish in future interactions. ${ }^{26}$

\section{The role of Merger Law}

In this Section, I analyze how different merger laws affect the incentives for predation and mergers. Mergers creating or strengthening dominant positions are illegal according to the competition laws in most developed countries. Competition authorities typically implement these laws in a way which can roughly be described as "trying not to allow measured concentration to become too high" ${ }^{27}$ This type of merger law will here be referred to as the "restrictive merger law". If the target is failing, a merger leading to high concentration may nevertheless be accepted under the so-called failing firm defense. This type of law will also be studied. To focus on the difference between the restrictive merger law and the merger law including a failing firm defense, it is assumed that any merger between

\footnotetext{
${ }^{26}$ Note that the delayed merger might be unstable, since owner $d$ has an incentive to arrange separate bargaining with any of the strong firms.

${ }^{27}$ For instance, in the US, the Herfindahl-Hirschman Index (HHI) is used as a measure of concentration. The HHI is calculated by summing the squares of the individual market shares of all firms in the market.
} 
firms in the industry is blocked when the restrictive merger law is applied. ${ }^{28}$ This situation is the only of interest when comparing these laws, since if the merger where allowed under the restrictive merger law a failing firm defense would not affect the outcome.

More specifically, three merger law rules are considered. The first rule is a version of the restrictive merger law, according to which all mergers are assumed to be forbidden in the present case. This is referred to as the restrictive merger rule. The second and third rules are versions of the failing firm defense doctrine. The second rule is the existing US failing firm defense rule. The third rule, which is suggested here, is a modified version of the US rule, called the modified failing firm defense rule.

\subsection{The restrictive merger law}

The timing of the model is the same as in Section 3.2. There are thus four periods to consider.

Period 4. The remaining firms have no incentive to predate, since this is the last period. The firms thus compete in standard fashion and generate profits.

Period 3. No mergers occur in the third period due to the restrictive merger law. Consequently, firm $d$ exits, if it is bankrupt.

Period 2. No mergers are allowed in period 1 according to the restrictive merger law, and there will thus be four firms in the industry in period 2. Since I restrict the analysis to symmetric equilibria, it is sufficient to consider one of the strong firms' incentive to predate, firm 1, say. Firm 1's profits over periods 2 and 4 when predating are $\pi_{1}(1,1,1, d)-\frac{\bar{x}}{3}+\pi_{1}(1,1,1,0)$, since no mergers are allowed in period 3 and firm $d$ exits after predation. If firm 1 does not predate, its profits over periods 2 and 4 are $\pi_{1}(1,1,1, d)+\pi_{1}(1,1,1, d)$, since no mergers are allowed in period 3. Thus firm 1 predates in period 2 if and only if C3' holds:

C3' $\pi_{1}(1,1,1, d)-\frac{\bar{x}}{3}+\pi_{1}(1,1,1,0)>2 \pi_{1}(1,1,1, d)$

Period 1. No mergers are allowed in period 1 according to the restrictive merger law.

The market structure in period 4 will thus be a quadropoly if predation does not occur in period 2 and a triopoly if predation occurs in period 2 . Let $x^{s}$ be the cost at which the strong firms are indifferent to predating or not predating in period 2. Thus we have the following result:

\footnotetext{
${ }^{28}$ This assumption puts restrictions on the underlying oligopoly model. Basically, it means that the merger increases concentration in a non-neglible way and that cost savings associated with the merger are limited.
} 
Lemma 5. Under the restrictive merger law, the equilibrium market structure is (i) a quadropoly if $\bar{x}>x^{s}$ and (ii) a triopoly if $\bar{x}<x^{s}$.

\subsection{The US failing firm defense}

Let us turn to the case where interaction between the firms takes place under the US 1992 Merger Guidelines, which state that an otherwise anti-competitive merger may be permitted if four conditions are met: l) the allegedly failing firm would be unable to meet its financial obligations in the near future; 2) it would not be able to reorganize successfully under Chapter 11 of the Bankruptcy Act; 3) it has made unsuccessful good-faith efforts to elicit reasonable alternative offers of acquisition of the assets of the failing firm ${ }^{29}$ that would both keep its tangible and intangible assets in the relevant market and pose a less severe danger to competition than does the proposed merger; and 4) absent the acquisition, the assets of the failing firm would exit the relevant market.

The first condition requires that the failing firm must be unable to meet its financial obligations. The second condition ensures that the firm does not only have short-term difficulties, but is also not viable in the long run. These two conditions are fulfilled if the prey is bankrupt. Moreover, in this set-up, Condition 4 is fulfilled if and only if Condition 3 is fulfilled, since it is assumed that the failing firm will be liquidated, and thus exit, if not acquired. Hence, the 1992 failing firm defense is valid in my set-up if, and only if, Condition 3 is satisfied. Condition 3 refers to an alternative buyer that would pose less severe danger to competition. It is assumed that this is interpreted by the authority as a firm with a smaller market share. Furthermore, this alternative buyer must make a reasonable offer, which I interpret as the highest bid from a firm outside the industry.

In order to incorporate these restrictions into the merger formation model, some more notation is required. ${ }^{30}$ Let owner $e$ be an owner who will use the prey's assets outside the industry. The valuation of obtaining the bankrupt firm's assets for owner $e$ is denoted $v_{e d^{p}}^{e}$, and owner $e$ 's bid is denoted $b_{e}^{d}$. It is assumed that the assets in the industry are partly industry specific: owner $e$ 's valuation of obtaining the assets is lower than the value for firms in the industry of obtaining the assets if the assets would otherwise exit the industry, i.e. $v_{e d^{p}}^{e}<v_{i d^{p}}^{i e}$. In order to ensure that owner $e$ does not obtain any of the strong firms' assets, it is assumed that the insiders' assets are of no value to owner $e$ and to ensure that no insider obtains owner $e$ 's assets, it is assumed that owner $e$ 's assets are of no value to the insiders.

\footnotetext{
${ }^{29}$ Any offer to purchase the assets of the failing firm for a price above the liquidation value of those assets - the highest valued use outside the relevant market or equivalent offer to purchase the stock of the failing firm - will be regarded as a reasonable alternative offer.

${ }^{30}$ For a more detailed discussion of the failing firm defense doctrine see Persson (1998).
} 
Some more notation is needed, in order to formalize the US failing firm defense rule. Let firm $i$ 's market share be denoted by $s_{i} \equiv \frac{q_{i}}{Q}$. Furthermore, let $\mathbf{s}$ be an arbitrary vector of market shares in the industry. Let firm 1 be the largest firm in the industry, firm 2 the second largest, etc., and let $h$ be defined: $h=\max \{i$ : $\left.b_{i} \geq b_{e}^{d}\right\}$. Then $h$ is the smallest firm in the industry that posts a bid at least as high as the bid posted by the external firm. If the firms are identical, it is assumed that after the bidding has taken place, the competition authority picks one of the firms with equal probability of being the smallest. ${ }^{31}$ The failing firm defense allocation rule, $S^{f}(\mathbf{b}, \mathbf{s}, i)$, is defined:

Definition 4. $S^{f}(\mathbf{b}, \mathbf{s}, i)=\left\{\begin{array}{c}i ; \text { for } i \neq d \\ h \text { if } h \text { exists, e otherwise; for } i=d\end{array}\right\}$

Thus, all assets owned by non-bankrupt owners stay with their original owners, and owner $d$ 's assets are sold either to one of the strong firms or to the outside firm.

Period 4. The remaining firms have no incentive to predate, since this is the last period. The firms thus compete in standard fashion and generate profits.

Period 3. There are four firms in the industry, since no mergers are allowed in period 1 according to the US failing firm defense rule. For the same reason, no mergers are allowed in period 3 , if firm $d$ is not bankrupt. If firm $d$ is bankrupt, its assets are sold. The outcome under the US failing firm defense rule is described in the following Lemma:

Lemma 6. If firm $d$ is bankrupt in period 3, owner $i \neq d$, e obtains owner $d$ 's assets at a price equal to the value of the assets outside the industry, $v_{e d p}^{e}$.

Proof. See Appendix.

Note that the US failing firm defense rule restricts the bidding competition between the firms in the industry, since the assets can only be obtained by the smallest firm in the industry with a bid above the outsider's. ${ }^{32}$

Period 2. There are four firms in the industry since, according to the US failing firm defense rule, no mergers are allowed in period 1. Since I restrict the analysis to symmetric equilibria, it is sufficient to look at one of the strong firm's incentive to predate, firm 1 say. Firm 1's profit when predating is given by

\footnotetext{
${ }^{31}$ This assumption seems compatible with the situation where the competition authority cannot perfectly observe the firms' market share, but uses estimates.

${ }^{32}$ Note that this type of auction with externalities gets much more involved when the potential buyers are asymmetric. However, the important thing for the result here is that the acquisition price under the failing firm defense never exceeds the value of the assets outside the industry. This is shown to hold also for asymmetric firms, see Persson (1998).
} 
$\pi_{1}(1,1,1, d)-\frac{\bar{x}}{3}+\frac{2}{3} \pi_{1}\left(1,1+d^{p}, 1,0\right)+\frac{1}{3}\left(\pi_{1}\left(1+d^{p}, 1,1,0\right)-v_{e d^{p}}^{e}\right)$, since owner 1 obtains the prey's assets with the probability of $\frac{1}{3}$, and does not with the probability of $\frac{2}{3}$, when firm $d$ is bankrupt in period 3. The profit for firm 1 when not predating is $\pi_{1}(1,1,1, d)+\pi_{1}(1,1,1, d)$, since no mergers are allowed in period 3 if firm $d$ is not bankrupt. Consequently, firm 1 predates if and only if C3" holds:

$$
\text { C3" } \begin{aligned}
& \pi_{1}(1,1,1,1)-\frac{\bar{x}}{3}+\frac{2}{3} \pi_{1}\left(1,1+d^{p}, 1,0\right)+\frac{1}{3}\left(\pi_{1}\left(1+d^{p}, 1,1,0\right)-v_{e d^{p}}^{e}\right) \\
& >2 \pi_{1}(1,1,1, d)
\end{aligned}
$$

Period 1. Since no firm is bankrupt, no mergers are allowed according to the US failing firm defense.

The market structure in period 4 is hence a quadropoly if the strong firms do not predate in period 2, and a triopoly if the strong firms predate in period 2. Let $x^{f}$ denote the cost at which the strong firms are indifferent to predation or non-predation in period 2. Thus we have the following result:

Lemma 7. Under the US failing firm defense, the equilibrium market structure is (i) a quadropoly if $\bar{x}>x^{f}$ and (ii) a triopoly if $\bar{x}<x^{f}$.

\subsection{The modified failing firm defense}

Let us now turn to a modified version of the US failing firm defense, a rule that is presented here. It is identical to the rule in the US 1992 Merger Guidelines, apart from the last two conditions being omitted. Thus, only mergers with bankrupt firms are allowed and the bidder with the highest bid obtains the bankrupt firm's assets. This corresponds to the situation under the bankruptcy rule, described in Section 3, with the restriction that no mergers between non-bankrupt firms are allowed. ${ }^{33}$

Period 4. The remaining firms have no incentive to predate, and thus compete in standard fashion.

Period 3. There are four firms in the industry, since no mergers are allowed in period 1. If firm $d$ is not bankrupt, no mergers are allowed. If firm $d$ is bankrupt, Lemma 2 applies, since no other mergers are allowed and since it is assumed that $v_{e d^{p}}^{e}<v_{i d^{p}}^{i e}$. Thus, firm $d$ is acquired by one of the strong firms at the price $v_{i d^{p}}^{i j}$.

Period 2. There are four firms in the industry, since no mergers are allowed in period 1. Since I restrict the analysis to symmetric equilibria and since all mergers between non-bankrupt firms are forbidden, Lemma 4 applies. Thus the strong firms predate iff C3 holds.

\footnotetext{
${ }^{33}$ Note that the merger formation model in this situation corresponds to the auction models provided by Jehiel and Moldovanu (1996).
} 
Period 1. No mergers are allowed according to the modified failing firm defense rule.

Consequently, the market structure in period 4 is a quadropoly if the strong firms do not predate in period 2 and it is a triopoly if the strong firms predate in period 2. Let $x^{l}$ be the cost at which the strong firms are indifferent between predating or not predating in period 2. Then, there is no predation when $\bar{x}>x^{l}$ and predation when $\bar{x}<x^{l}$. Thus we have the following result:

Lemma 8. Under the modified failing firm defense, the equilibrium market structure is (i) a quadropoly if $\bar{x}>x^{l}$ and (ii) a triopoly if $\bar{x}<x^{l}$.

\subsection{The equilibrium market structure under the different merger laws}

Let us now compare how the different merger laws affect the emerging market structure. The following result can be derived from Lemma 5, Lemma 7 and Lemma 8:

Proposition 5. The equilibrium market structure is (1) at least as concentrated under the restrictive merger law as under the modified failing firm defense and more concentrated for some parameter values (2) at least as concentrated under the US failing firm defense as under the modified failing firm defense and more concentrated for some parameter values (3) more concentrated under the US failing firm defense than under the restrictive merger law for some parameter values.

Proof. See Appendix.

The results suggest that a restrictive merger policy, the restrictive merger law, might be counterproductive, in the sense that it leads to concentration. It may increase the incentives for predation by helping predators avoid a bidding competition for the prey after predation has occurred. Consequently, the incentive for predation for mergers under a failing firm defense is limited if the potential buyers compete to acquire the failing firm. On the other hand, the incentive for predation for merger under the US failing firm defense might be strong since it allows mergers but limits the bidding competition by favoring small firms in the acquisition process.

Under the restrictive merger law, the market structure might not only be the one with the smallest number of firms, but also the one with the smallest industry capital stock. This is due to the fact that the prey's assets exit under the restrictive merger law, whereas they might be obtained by a rival under the failing firm defense policies. Thus, the restrictive merger law might not only lead to few firms in the industry, but also to a situation where these small firms only have a small amount of capital. 
Conditions C3, C3' and C3" can be generalized to the $n$-strong-firm case. Hence, the logic of the proof of Proposition 5 may be applied to show that the results here generalize to situations with a larger number of firms.

\section{Concluding Remark}

In this paper it has been argued that in a multi-firm setting predation is less prone to the free-rider problem than mergers are. The reason is that mergers by definition concentrate the costs of eliminating a rival with one firm; whereas predation allows the cost to be spread out more evenly among the firms. This implies that predation might be rational in a multi-firm setting.

Moreover it has been shown that predators prefer predation technologies that destroy the prey's assets. This is counterintuitive at first since one might think that the prey's assets might be valuable to predators if acquired in a later merger stage. The reason is that any benefits from acquiring the prey's assets are competed away in the bidding competition among the potential buyers. All that is left are any negative externalities on rivals the acquired assets might generate, externalities that might be mitigated by destroying the prey's assets. Thus a second rational for predation in a multi-firm setting is that it might limit the negative effects of the bidding competition for the prey.

The analysis has also suggested that, contrary to received wisdom, relaxing merger policy to allow a falling-firm defense may reduce concentration. The reason is that a failing-firm defense induces the firms to engage in a bidding war for the dying prey which may be so costly as to induce the firms not to prey to begin with. Consequently, the incentive for predation for merger under a failing firm defense is limited, if the potential buyers compete to acquire the failing firm. On the other hand, the incentive for predation for merger under the US failing firm defense might be strong, since it allows mergers but limits the bidding competition by favoring small firms in the acquisition process. Thus, if the welfare costs of concentrated market structures are high, i.e. involve large dead weight losses, the existing merger laws thus seem unsuitable. The modified failing firm defense suggested here, where firms compete to buy the failing firm, then seems more appropriate. ${ }^{34}$ However, as shown by Persson (1998), one might also argue the importance of taking the efficiency argument into account when designing a policy for the selling of a failing firm. The challenge is then to construct a rule allocating the failing firm's assets in a socially efficient way, without creating strong incentives for predation.

\footnotetext{
${ }^{34}$ However, this rule might increase the incentive for the use of destructive predation technologies.
} 
The results in this paper also have implications for another practice of the competition authority: the "divestment requirement", i.e. the merging parties must sell some of their assets to rivals. The "divestment requirement" might be counterproductive, since it might "help" firms avoid the free-riding problem and limit the negative effects of the bidding competition. 


\section{Appendix}

\section{Proof of Lemma 1}

Consider the situation where all firms post an asking price at $\pi_{i}(4,0,0,0)+\varepsilon$, say, and a bid at $\pi_{i}(1,1,1,1)-\varepsilon$, say. It follows directly that this is a Nash equilibrium since no owner can become better-off by lowering his asking price and becoming a seller, or by raising his bid and becoming a buyer, or both.

Let us now turn to a merged equilibrium candidate. Let owner 1 be the owner with most assets in equilibrium, without loss of generality. Denote the number of assets he possesses with $k_{1}=n-m$ for $m \geq 0$, where $n$ is the total number of assets, which equals 4 . Let $\pi_{1}^{\prime}$ denote the first owner's profits and let $\pi_{1}^{\prime \prime}$ be his profits if he lowers his bid to the $k_{1}-1$ sellers and becomes a non-buyer when all other firms maintain their ownership. He can do better if one of the other owners buys any of the assets which he abstains from buying, since an outsider benefits when other firms merge according to Assumption 1. Thus, this is a sufficient condition for owner 1 to have an incentive to deviate. The first owner is unwilling to pay the $k_{1}-1$ sellers more than $\pi_{1}^{\prime}-\pi_{1}^{\prime \prime}$. Consider next one of the $k_{1}-1$ sellers, say the second owner. If he unilaterally deviates and raises his asking price above the first owner's bid, his assets will not be bought, and he will realize a profit of $\pi_{2}^{\prime \prime \prime}$. It follows that the first owner has to pay each seller at least $\pi_{2}^{\prime \prime \prime}$ or at least $(4-m-$ 1) $\pi_{2}^{\prime \prime \prime}$ to all of them. Consequently, such an equilibrium is impossible if $\pi_{1}^{\prime}-\pi_{1}^{\prime \prime}<$ $(4-m-1) \pi_{2}^{\prime \prime \prime}$. There are four possible market structures which involve a merger, i.e. $m \in\{0,1,2\}:$ (i) the monopoly structure, $m=0$, then $\pi_{1}^{\prime}=\pi_{1}(4,0,0,0)$, $\pi_{1}^{\prime \prime}=\pi_{1}(1,1,1,1)$ and $\pi_{2}^{\prime \prime \prime}=\pi_{2}(3,1,0,0)$. Thus the monopoly structure is not stable if $\pi_{1}(4,0,0,0)-\pi_{1}(1,1,1,1)<3 \pi_{2}(3,1,0,0)$. Using the same reasoning, the following can be shown for the other possible market structures involving mergers: (ii) the asymmetric duopoly structure, $m=1$, which is not stable if $\pi_{1}(3,1,0,0)-\pi_{1}(1,1,1,1)<2 \pi_{2}(2,1,1,0)$, (iii) the symmetric duopoly structure, $m=2$, which is not stable if $\pi_{1}(2,2,0,0)-\pi_{1}(1,2,1,0)<\pi_{2}(2,1,1,0)$, and (iv) the triopoly structure, $m=2$, which is not stable if $\pi_{1}(2,1,1,0)-\pi_{1}(1,1,1,1)<$ $\pi_{2}(1,1,1,1)$. Thus there are no mergers if $\mathrm{C} 1$ holds.

\section{Proof of Lemma 2}

Consider first the equilibrium candidate where owner 1 , 2 , or 3 acquires owner $d$ 's assets. Note that owner $d$ cannot obtain any assets according to Definition 3. Consider the equilibrium candidate $\mathbf{b}^{*}$, where $b_{i}^{d *} \geq b_{j}^{d *} \geq 0, j \neq i$. Let owner $i$ be the owner obtaining the assets. Note that $b_{i}^{d *}>v_{i d^{p}}^{i j}$ is a weakly dominated strategy, since no owner will post a bid over its maximum valuation of obtaining the assets. If $b_{i}^{d *}<v_{j d^{p}}^{j i}$, owner $j$ benefits from deviating to $b_{j}^{d}=b_{i}^{d *}+\varepsilon$, since he then obtains the assets according to Definition 3 and pays a price for the assets which is lower than his valuation of obtaining them. Last, consider the candidate 
$b_{i}^{d *}=b_{j}^{d *}=v_{j d^{p}}^{j i}$. Then no owner has an incentive to deviate. Thus, this is a Nash equilibrium and the only one where owner 1,2 , or 3 acquires owner $d$ 's assets. Let the remaining bids and asks in $\mathbf{b}^{*}$ consist of an asking price at $\pi_{i}(4,0,0,0)+\varepsilon$, say, and a bid at $\pi_{i}(1,1,1,1)-\varepsilon$, say. It follows directly that these asks and bids are also a Nash equilibrium, since no owner can become better-off by lowering his asking price and becoming a seller, or by raising his bid and becoming a buyer, or both. Thus $\mathbf{b}^{*}$ is a Nash equilibrium.

Let us now show that all structures, except the triopoly structure where owner 1,2 , or 3 acquires owner $d$ 's assets, are not equilibrium structures.

First consider the quadropoly. In this structure, all owners have posted negative bids on owner $d$ 's assets, since one of them will otherwise obtain firm $d$ 's assets according to Definition 3. But, then owner $i$ has an incentive to deviate to $b_{i}=0$ since $v_{i d^{p}}^{i d}>0$. Thus, the quadropoly is not a Nash equilibrium.

Second, consider any merged equilibrium involving a merger between at least two of the strong owners and possibly owner $d$. First, note that if $d$ is not acquired, all owners have posted negative bids on owner $d$ 's assets. But, then owner $i$ has an incentive to deviate to $b_{i}=0$ since $v_{i d^{p}}^{i d}>0$. Thus, in equilibrium, owner $d$ participates in a merger. Let $\pi_{1}^{\prime}$ denote the first owner's profits and let $\pi_{1}^{\prime \prime}$ be his profits if he lowers his bid to the $k_{1}-1$ sellers and becomes a non-buyer when all other firms maintain their ownership. The first owner is unwilling to pay the $k_{1}-1$ sellers more than $\pi_{1}^{\prime}-\pi_{1}^{\prime \prime}$. Consider next one of the $k_{1}-1$ sellers except owner $d$, the second owner, say. If he deviates and raises his asking price above the first owner's bid, his assets will not be bought and he will realize a profit of $\pi_{2}^{\prime \prime \prime}$. The first owner then has to pay each seller, except $d$, at least $\pi_{2}^{\prime \prime \prime}$ or at least $(3-m-1) \pi_{2}^{\prime \prime \prime}$ to all of them. Consequently, such an equilibrium is impossible if $\pi_{1}^{\prime}-\pi_{1}^{\prime \prime}<(3-m-1) \pi_{2}^{\prime \prime \prime}$. There are three possible market structures involving this kind of merger: (i) the monopoly structure, which is not stable if $\pi_{1}\left(3+d^{p}, 0,0,0\right)-\pi_{1}\left(1,1+d^{p}, 1,0\right)<2 \pi_{2}\left(2+d^{p}, 1,0,0\right)$, (ii) the asymmetric duopoly structure, which is not stable if $\pi_{1}\left(2+d^{p}, 1,0,0\right)-\pi_{1}\left(1,1+d^{p}, 1,0\right)<$ $\pi_{2}\left(1+d^{p}, 1,1,0\right)$, and (iii) the symmetric duopoly structure, which is not stable if $\pi_{1}\left(2,1+d^{p}, 0,0\right)-\pi_{1}\left(1,1,1+d^{p}, 0\right)<\pi_{2}\left(1,1,1+d^{p}, 0\right)$. Thus there is no such mergers if $\mathrm{C} 2$ holds.

\section{Proof of Lemma 3}

(i) Consider the case where predation is profitable for the strong firms as a group. Consider the symmetric equilibrium candidate $x^{*}=\frac{\bar{x}}{n-1}$. Firm $i \neq$ $1, d$ has no incentive to deviate to $x^{\prime}<\frac{\bar{x}}{n-1}$, since firm $d$ is then not bankrupt and firm $i$ 's investment gives no benefits, but only costs. If firm $i$ deviates to $x^{\prime}>\frac{\bar{x}}{n-1}$, firm $d$ is still bankrupt, but firm $i$ pays more. Note that another symmetric Nash equilibrium might exist: all firms provide zero. However, the first 
Nash equilibrium Pareto dominates the second, since it assumed that predation is profitable for the group of predators.

Note that it follows that any symmetric equilibrium candidate, $x^{\prime}$, where $x_{i}>$ $\frac{\bar{x}}{n-1}$ is not an equilibrium. The reason is that firm $i$ has an incentive to deviate to $x^{\prime \prime}=x^{\prime}-\varepsilon$, since firm $d$ will still be bankrupt, but firm $i$ pays less. Furthermore, any symmetric equilibrium candidate, $x^{\prime}$, where $x_{i} \in\left(0, \frac{\bar{x}}{n-1}\right)$ is not an equilibrium. The reason is that firm $i$ has an incentive to deviate to $x^{\prime \prime}=x^{\prime}-\varepsilon$, since firm $d$ will still not be bankrupt, but firm $i$ pays less.

(ii) Consider the case where predation is not profitable for the group of strong firms. Consider the symmetric equilibrium candidate $x^{*}=0$. Firm $i \neq 1, d$ has no incentive to deviate to $x^{\prime} \in(0, \bar{x})$ since firm $d$ is still not bankrupt and firm $i$ 's investment only incurs costs. If firm $i$ deviates to $x^{\prime}>\bar{x}$, firm $d$ will be bankrupt, but firm $i$ pays more than its profit increases, since it is assumed that predation is not profitable for the group of strong firms.

Note that it follows that any symmetric equilibrium candidate, $x^{\prime}$, where $x_{i} \in$ $\left(0, \frac{\bar{x}}{n-1}\right)$ is not an equilibrium. The reason is that firm $i$ has an incentive to deviate to $x^{\prime \prime}=x^{\prime}-\varepsilon$, since firm $d$ will still not be bankrupt, but firm $i$ pays less. Furthermore, any symmetric equilibrium candidate, $x^{\prime}$, where $x_{i}=\frac{\bar{x}}{n-1}$, is not an equilibrium. The reason is that firm $i$ has an incentive to deviate to $x^{\prime \prime}=0$, since firm $d$ will not be bankrupt, but firm $i$ pays more than its profit increases, since it is assumed that predation is not profitable for the group of strong firms. Finally, any symmetric equilibrium candidate, $x^{\prime}$, where $x_{i}>\frac{\bar{x}}{n-1}$, is not an equilibrium. The reason is that firm $i$ has an incentive to deviate to $x^{\prime \prime}=x^{\prime}-\varepsilon$, since firm $d$ will still be bankrupt, but firm $i$ pays less.

\section{Proof of Proposition 1}

According to Lemma 1, there is no merger when predation is not an option and $\mathrm{C} 1$ holds. On the other hand, the strong firms predate in period 2 and acquire owner d's assets in period 3 according to Lemma 4 and Lemma 2, when C1, C2 and C3 hold. The fact that C1, C2 and C3 can hold simultaneously, which is shown in the linear model in the Appendix, completes the proof .

\section{Proof of Proposition 2}

Let $\mathrm{C} 1$ and $\mathrm{C} 2$ hold, then the strong firms predate in period 2 iff $\mathrm{C} 3$ holds according to Lemma 4 . Using symmetry, it can be shown that C3 holds iff $-\frac{\bar{x}}{3}+$ $\pi_{2}\left(1+d^{p}, 1,1,0\right)>\pi_{1}(1,1,1,1)$. The predation technology only affects $\pi_{2}(1+$ $\left.d^{p}, 1,1,0\right)$ in this inequality. It then follows that $C 3$ is most likely to hold when $\pi_{2}\left(1+d^{p}, 1,1,0\right)$ is maximized, which occurs when owner $d$ 's assets are worthless. Moreover, the net profit from predating for a strong firm is $\pi_{2}\left(1+d^{p}, 1,1,0\right)$. Consequently, the strong firms choose the destructive predation technology, since $\pi_{2}\left(1+d^{p}, 1,1,0\right)$ is then maximized. 


\section{Proof of Proposition 4}

First note that no firm predates in period 4 , since this is the last period. In period 3, firm $d$ is acquired by one of the strong firms, if it is bankrupt. To see this, note that Lemma 2 applies, since mergers between the non-bankrupt firms are ruled out by Assumption 3. If firm $d$ is not bankrupt, it follows direct from Assumption 3 that no mergers occur. In period 2, the strong firms predate in any market structure by assumption. Then two equilibria exist in period 1:

(i) Consider the equilibrium candidate $\mathbf{b}^{*}$ where owner 1,2 , or 3 acquires owner $d$ 's assets. Let owner $i$ be the owner obtaining the assets. Then, note that $b_{i}^{d *}>v_{i d}^{i j}$ is not an equilibrium strategy, since it is a dominated strategy. If $b_{i}^{d *}<v_{j d}^{j i}$, owner $j$ benefits from deviating to $b_{j}^{d}=b_{i}^{d *}+\varepsilon$, since he then obtains the assets according to the laissez-faire rule and pays a price for the assets which is lower than his valuation of obtaining them. Consider next the candidate $b_{i}^{d *}=v_{j d}^{i j}>b_{d}^{d *}$. Then, no owner $l \neq d$ has an incentive to deviate, since they are indifferent. Furthermore owner $d$ has no incentive to deviate, since $b_{i}^{d *}=v_{j d}^{i j}>$ $v_{d d}^{d i}$, when $z=0$. Thus, this is a Nash equilibrium and the only symmetric Nash equilibrium where owner 1,2 , or 3 acquires owner $d$ 's assets. Note that there are no other mergers according to Assumption 3.

(ii) Consider the situation where owner $d$ posts an asking price at

$2 \pi_{i}^{M}(4,0,0,0)+\varepsilon$, say, and the strong owners bid for firm $d$ at $z+v_{i d^{p}}^{i j}-\varepsilon$, say. It follows directly that this is a Nash equilibrium, since no owner can become better-off by lowering his asking price and becoming a seller, or by raising his bid and becoming a buyer, or both. Note that no other mergers can take place according to Assumption 3.

\section{Proof of Lemma 6}

First note that according to the US failing firm defense rule, owner $i \neq d$ acquiring owner $d$ 's assets is the only possible acquisition. Recall that owners 1 , 2 and 3 are symmetric and I therefore assume that $b_{1}^{d}=b_{2}^{d}=b_{3}^{d}$ in equilibrium. Consider the equilibrium candidate $b^{d *}: b_{i}^{d *} \geq b_{e}^{d *}, i \neq d$,e. Then owner $i$ obtains owner $d$ 's assets according to Definition 4 . First note that $b_{e} \leq v_{e d p}^{e}$, since $b_{e}>v_{e d^{p}}^{e}$ is a weakly dominated strategy. If $b_{i}^{d *}>v_{e d p}^{e}$, then owner $i$ knows that with the probability of $\frac{1}{3}$, he is considered the smallest agent and therefore he obtains the assets. Then he benefits from deviating to $b_{i}^{d}=v_{e d^{p}}^{e}$, since he still obtains the assets according to Definition 4, but pays a lower price. On the other hand, if he is not considered the smallest agent, his payoff will not change if he deviates. Accordingly, he will deviate, since he gains with the probability of $\frac{1}{3}$, and his payoff does not change with the probability of $\frac{2}{3}$. If $b_{i}^{d *}<v_{e d^{p}}^{e}$, then owner $e$ has an incentive to deviate to $b_{e}^{d}=b_{i}^{d *}+\varepsilon$, since he will then obtain the assets according to Definition 4, but pay a price lower than his valuation of obtaining 
them. Last consider the candidate $b_{i}^{d *}=v_{e d^{p}}^{e}$. Then, no owner has an incentive to deviate. Thus $b_{i}^{d *}=v_{e}^{e}$ is the only Nash equilibrium where owner $i$ obtains the assets.

Consider now the equilibrium candidate $b^{d * *}: b_{e}^{d * *} \geq b_{i}^{d * *}, i \neq d, e$. Then owner $e$ obtains the prey according to Definition 4 . Note that $b_{e} \leq v_{e d^{p}}^{e}$, since $b_{e}>v_{e d^{p}}^{e}$ is a weakly dominated strategy. But owner $i$ might then deviate to $b_{i}^{d}=b_{e}^{d * *}+\varepsilon$ and obtain the assets according to Definition 4, but pay a price lower than his valuation of obtaining them, since $v_{i d^{p}}^{i e}>v_{e d^{p}}^{e}$. Thus, owner $e$ will not obtain the assets in equilibrium.

\section{Proof of Proposition 5}

Consider first the restrictive merger rule. Then, according to Lemma 5, the equilibrium market structure will be a triopoly iff $\bar{x}<x^{s}$. Second, consider the US failing firm defense rule. Then, according to Lemma 7 , the equilibrium market structure will be a triopoly iff $\bar{x}<x^{f}$. Finally, consider the modified failing firm rule. Then, according to Lemma 8 , the equilibrium market structure will be a triopoly iff $\bar{x}<x^{l}$. 0 .

(1) Using symmetry, we have that $x^{s}-x^{l}=3\left(\pi_{2}(1,1,1,0)-\pi_{2}\left(1+d^{p}, 1,1,0\right)\right)>$

(2) We have that $x^{f}-x^{l}=\left(2 \pi_{1}\left(1,1+d^{p}, 1,0\right)+\pi_{1}\left(1+d^{p}, 1,1,0\right)-v_{e d p}^{e}\right)-$ $3 \pi_{1}(1,1,1, d)-\left(3\left(\pi_{2}\left(1+d^{p}, 1,1,0\right)-\pi_{1}(1,1,1, d)\right)\right)$. Using symmetry, the equality can be rewritten: $\pi_{1}\left(1+d^{p}, 1,1,0\right)-v_{e d^{p}}^{e}-\pi_{2}\left(1+d^{p}, 1,1,0\right)>0$, since $\pi_{1}(1+$ $\left.d^{p}, 1,1,0\right)-\pi_{2}\left(1+d^{p}, 1,1,0\right)=v_{i d^{p}}^{i j}>v_{e d^{p}}^{e}$.

(3) We have that $x^{s}-x^{f}=\left(3\left(\pi_{1}(1,1,1,0)-\pi_{1}(1,1,1,3)\right)\right)-\left(\left(2 \pi_{2}(1+\right.\right.$ $\left.\left.\left.d^{p}, 1,1,0\right)+\pi_{1}\left(1+d^{p}, 1,1,0\right)-v_{e d^{p}}^{e}\right)-3 \pi_{1}(1,1,1, d)\right)$. By using symmetry, the equality can be rewritten: $3 \pi_{1}(1,1,1,0)-\left(2 \pi_{2}\left(1+d^{p}, 1,1,0\right)+\pi_{1}\left(1+d^{p}, 1,1,0\right)-v_{e d^{p}}^{e}\right) \lesseqgtr$ 0 , if $3 \pi_{1}(1,1,1,0)>\pi_{2}\left(1+d^{p}, 1,1,0\right)+\pi_{1}\left(1+d^{p}, 1,1,0\right)$, which is the case in many oligopoly models, since $v_{e d^{p}}^{e} \in\left(0, v_{i d^{p}}^{i e}\right)$.

\section{Proof of the statement in Proposition 1: C1, C2 and C3 can hold simultaneously.}

Let $\bar{x}=0$ then in the linear model

C1 (i) $\frac{1}{4}-\frac{1}{25}-3 \frac{1}{9}=-2.9011<0$

(ii) $\frac{1}{9}-\frac{1}{25}-2 \frac{1}{16}=-1.9914<0$

(iii) $\frac{1}{9}-\frac{1}{16}-\frac{1}{16}=-1.3889 \times 10^{-2}<0$

and (iv) $\frac{1}{16}-\frac{1}{25}-\frac{1}{25}=-0.0175<0$

C2 (i) $\frac{1}{4}-\frac{1}{16}-2 \frac{1}{9}=-1.9236<0$

(ii) $\frac{1}{9}-\frac{1}{16}-\frac{1}{16}=-1.3889 \times 10^{-2}<0$ 
and (iii) $\frac{1}{9}-\frac{1}{16}-\frac{1}{16}=-1.3889 \times 10^{-2}<0$

C3 $\frac{1}{25}+\frac{1}{16}-\frac{2}{25}=0.0225>0$. 


\section{References}

[1] Appelbaum, E. and Weber, S., "A Note on the Free Rider Problem in Oligopoly," Economics Letters, 1992, Vol. 40, 473-480.

[2] Bolton, P. and Scharfstein, D. S., "A Theory of Predation Based on Agency Problems in Financial Contracting," American Economic Review, March 1990, Vol. 80, 93-106.

[3] Deneckere, Raymond and Davidson, Carl, "Incentives to Form Coalitions with Bertrand Competition," Rand Journal of Economics, Winter 1985, Vol. $16,473-486$.

Farrell, J and Shapiro, C, "Asset Ownership and Market Structure in Oligopoly," RAND Journal of Economics, Summer 1990b, Vol. 21, 275-292.

[4] Gilbert, R., and Vives., X., "Entry Deterrence and the Free-Rider Problem," Review of Economic Studies, 1986, 53, 71-83.

[5] Jehiel, P. and Moldovanu, B., "Strategic Nonparticipation," RAND Journal of Economics, Spring 1996, Vol. 27, 84-98.

[6] Kamien, M. I. and Zang, I., "The Limits of Monopolization Through Acquisition," Quarterly Journal of Economics, May 1990, 2, 465-99.

[7] Kamien, M. I. and Zang, I., "Competitively Cost Advantageous Mergers," Games and Economic Behaviors, 1991, 3, 323-338.

[8] Kamien, M. I. and Zang, I., "Monopolization by Sequential Acquisition," Journal of Law, Economics \& Organization, 1993, V9, N2, 205-229.

[9] Kovenock, D., and Roy, S., "Free Riding in Non-Cooperative Entry Deterrence with Differentiated Products," Mimeo, Purdue University, 1995.

[10] Kwoka, JR. J. E., and White, L. J., "The Antitrust Revolution," HarperCollinsCollegePublishers, 1994.

[11] McAfee, R. Preston and Williams, Michael A., "Horizontal Mergers and Antitrust Policy", Journal of Industrial Economics, June 1992, XL, 181-187.

[12] McGee, J. S., "Predatory Pricing Cutting: The Standard Oil (N.J.) Case," Journal of Law and Economics, 1958, Vol.1, 137-169.

[13] McGee, J. S., "Predatory Pricing Revisited," The Journal of Law and Economics, 1980, Vol. 23, 289-330. 
[14] Nolan, D., "Predatory Pricing in an Oligopolistic Framework," Mimeo, Royal Holloway College, University of London, 1998.

[15] Ordover, J. A. and Saloner, G., "Predation, Monopolization, and Antitrust," Handbook of Industrial Organization, Vol. 1, North-Holland, 1989.

[16] Perry, Martin K. and Porter, Robert H., "Oligopoly and the Incentive for Horizontal Merger," American Economic Review, 1985, 75, 219-27.

[17] Persson, L., "The Auctioning of a Failing Firm?," 1998. In L. Persson, Ph. D. Thesis, Stockholm University. Monograph Series, No. 35.

[18] Salant, Stephen W., Switzer, Sheldon and Reynolds, Robert J., "Losses Due to Merger: The Effects of an Exogenous Change in Industry Structure on Cournot-Nash Equilibrium," Quarterly Journal of Economics, 1983, 98, 18599.

[19] Saloner, G., "Predation, mergers, and incomplete information," RAND Journal of Economics, Summer 1987, Vol. 18, 165-186.

[20] Salop, S. C., and Scheffman, D. T., "Raising Rivals' Costs," American Economic Review, 1983, 73, 267-271.

[21] Stigler, G. J., "Monopoly and Oligopoly by Merger," American Economic Review, 1950, 40, 23-34.

[22] Yamey, B. S., "Predatory Price Cutting: Notes and Comments," The Journal of Law and Economics, 1972, Vol. 15, 129-142. 